\title{
The impact of food price increases on nutrient intake in Lebanon
}

\author{
Souhad Abou Zaki ${ }^{1}$, Jad Chaaban ${ }^{1}$, Lara Nasreddine ${ }^{2}$ and Ali Chalak ${ }^{1 *}$
}

\footnotetext{
* Correspondence: ac22@aub.edu.lb ${ }^{1}$ Department of Agricultural Sciences, Faculty of Agricultural and Food Sciences, American University of Beirut, P.O. Box 11-0236 Riad el Solh, Beirut 1107-2020, Lebanon Full list of author information is available at the end of the article
}

\begin{abstract}
We evaluate the impact of the recent increases in major food prices on the intake of essential nutrients in Lebanon, a small heavily import-dependent economy. Using nationally representative households' expenditure micro data, we derive food demand elasticities by estimating an Almost Ideal Demand System (AIDS) model, and then use these elasticities to evaluate the impact of rising prices on the intake of major macro/micronutrients among Lebanese households. Our results show that the intake of nutrients such as calcium, zinc, iron, and folate decreased significantly following the recent food price shocks, especially in central urban areas. Our results highlight the pressing need for public interventions to fight and prevent nutrients' deficiencies, especially in small import dependent economies.
\end{abstract}

Keywords: Almost ideal demand system; Food-price shocks; Food security; Lebanon; Nutrient intake

\section{Background}

The past eight years have been marked by a radical increase in international food prices. From 2006 to 2013, the FAO international food price index increased by 42 percent in real terms on average, with price of meats, dairy products, cereals, oils and sugars increasing by 31, 59, 60, 47 and 3.6 percent, respectively (FAO 2013). The literature on the implications of food-price shocks has focused mainly on the economic dimensions of the crisis. For instance, Ivanic and Martin (2008) estimated the effect of the $2005 / 2007$ food-price shock in 9 developing countries to be a 2.7-3 percent increase in the overall poverty rate. Yet an evaluation of the nutritional impacts of foodprice shocks remains central to any understanding of their full implications. When faced with a sharp decline in real incomes, households may be forced to alter their consumption and dietary habits, substituting expensive food items with cheaper ones or even reducing their consumption outright. Even though these substitutions may provide a feasible mechanism to escape hunger and cope with price shocks, they may be problematic as they would mask a more serious trade-off between nutritious food and cheap food especially when undertaken in the absence of adequate knowledge and understanding of their nutritional implications. Indeed, poor households may already be consuming the cheapest foods and varieties, such as grains, with very little room left for substitutions aimed at mitigating the deleterious nutritional effects of food-price increases (Jensen \& Miller 2008). This may increase the risk of malnutrition and nutrient deficiencies which, in addition for being an immediate health burden, may also impact

(C) 2014 Zaki et al.; licensee Springer. This is an Open Access article distributed under the terms of the Creative Commons Attribution License (http://creativecommons.org/licenses/by/2.0), which permits unrestricted use, distribution, and reproduction in any medium, provided the original work is properly cited. 
labor productivity in the short-run and school attendance and performance in the longrun (Behrman 1993).

Despite the overwhelming impact that high food prices may have, it remains a challenge to estimate their effect on consumers' nutritional well-being in developing countries due to data limitations and the lack of research in this area especially in the Middle East. (Jensen \& Miller 2008) examined the effects of the higher food prices recorded in 2005/2006 on the consumption and nutrition of the urban poor in two Chinese provinces, and theirs results showed that households did not experience significant reductions in caloric intake due to substitution between food items and government interventions. However, using changes in caloric intake as a sole indicator of households' nutritional status has been subject to criticism because of its sensitivity to climate and geographic changes (Cole \& Neumayer 2006), and because high-energy diets are not necessarily nutritious and healthy (Bowman 2006). An appropriate evaluation requires more representative and comprehensive indicators such as the changes in consumption of essential micronutrients. Recently, Ecker and Qaim (2011) attempted to quantify the nutritional effects of foodprice shocks in Malawi and evaluated the effectiveness of both income and price-related policies to improve nutrition, finding evidence in favor of the former. To date, there has been no study exploring the implications of food price increases on malnutrition in Middle Eastern countries, and our paper intends to fill in this gap.

This paper follows Ecker and Qaim's general framework to investigate the impact of the 2004/2008 food-price shock on the consumption of major food commodities and malnutrition in Lebanon, using the changes in macro/micronutrient intakes as a key indicator of the risk of malnutrition. We apply the Almost Ideal Demand System (AIDS) on a sample of 7,431 households, drawn from a national household survey conducted in 2004, to estimate food demand and nutrient elasticities, and quantify the effects of food price-price increases on various macro and micronutrients' intake levels. The rest of this paper is organized as follows: Section 'Food security in Lebanon' reviews the food security situation in Lebanon; Section 'Methods' describes the data and empirical strategy; Section 'Empirical model' presents the results and discusses them, and Section 'Results and discussion' concludes.

\section{Food security in Lebanon}

Even though Lebanon has not experienced severe hunger since the famine of World War I, it remains highly vulnerable to food-price shocks, mainly because of its heavy dependence on food imports. These amounted to 17 percent of its total merchandize imports in 2011 (World Bank 2013), and were comprised of a wide range of categories such as wheat, rice, sugar, soybean oil, maize, cattle, beef and veal (FAO 2010). While diversity is one remarkable feature of these imports, more alarming is their indispensability to domestic consumption which is best captured by imports to consumption ratios. In the 2005/2007 period, these ratios were 107, 88 and 101 percent for rice, soybean oil and refined sugar, respectively (FAO 2010), reflecting the depth of foodimports dependency. This dependency has been constantly amplified by the underperforming and poorly managed agricultural sector which suffers from the prevalence of traditional farming techniques and significant resource waste rendering it unable to meet the domestic demand for food and other agricultural commodities. Moreover, the country is already suffering from large current account and cash deficits amounting to 
24 and 9 percent of its GDP, respectively (World Bank 2013), which affects its ability to finance the increasing imports bills and contain the repercussions of the crisis.

At the micro level, Lebanese households experienced a severe reduction in their real incomes given the fact that they are net buyers of food and spend, on average, 20 percent of their incomes on agricultural commodities with higher percentages in peripheral areas (Central Administration of Statistics 2005). It is worth noting that the average income per capita in Lebanon is 740 \$ per month (World Bank 2013) and around 28.6 percent of the population live below the upper poverty line of $4 \$$ per day, 8 percent of whom live below the lower poverty line of $2 \$$ per day (UNDP 2013). Information on how households' food consumption changed as a result of the recent food crisis and the implications of these changes on households' nutrient intakes is virtually inexistent.

Various types of micronutrient deficiencies prevail in the country. Available data on the nutritional status of the Lebanese population indicate that the percentage of undernourished people in 2008 was 5 percent and the food deficit of undernourished people was $23 \mathrm{Kcal} /$ person/day (World Bank 2014). 11.5 percent of children are stunted and 16.7 percent are overweight (FAO 2010). Moreover, micronutrient deficiencies are common in Lebanon, most notably iron (Al Khatib et al. 2006; Hwalla, Adra, \& Jackson 2004) that is prevalent among in roughly a quarter of Lebanese women of child-bearing age, 12.8 percent of whom also suffered both folate and vitamin $\mathrm{B} 12$ deficiencies ( $\mathrm{Al}$ Khatib et al. 2006). Similarly, vitamin D and calcium dietary intakes were also found inadequate. Unpublished analysis of data from a 2008-2009 nationally representative "Nutrition and Non-Communicable Disease Risk Factor Survey" showed that 66.1 percent of adults consumed less calcium than recommended and 19.6 percent of these adults were vitamin D deficient with higher deficiency in females than males. The design and conduct survey are described in Nasreddine et al. (2012). Hence concerns about the repercussions of the crisis on food consumption and malnutrition become ever more legitimate.

\section{Methods \\ Data}

This study is based on the most recent comprehensive "National Survey of Household Living Conditions" of 2004 conducted by the Central Administration of Statistics (CAS) in association with the Ministry of Social Affairs (MoSA) and the United Nations Development Programme (UNDP) (MoSA, UNDP, \& CAS 2006). This 'Multi-Purpose Survey' (MPS) included detailed information on the demographic and social characteristics of households, their economic activities and housing conditions in addition to detailed figures on households' earnings, expenditures and quantities consumed of food and non-food items. The sample was nationally representative. The first "household characteristics and living conditions" questionnaire collected data on the demographic, educational and health background as well as the sources of income generated, housing characteristics and transportation. The second collected data on expenditures on specific goods and services made during the 12 months before the questionnaire. The third collected information on the items purchased and received for free and on gifts and meals for a period of 14 days recorded by the person in charge of the household's purchases. Finally, the fourth questionnaire collects the same information of the previous 
one but as reported by all the members of the household aged 15 and above. The data collection started on February 2004 and continued over a period of 54 weeks. The first questionnaire was completed by 13,003 households, while only a subset of 7,431 households answered the remaining three surveys on expenditures. Therefore our estimation sample was restricted to the 7,431 households for whom all types of data were available. Econometric estimation was performed using the statistical software Stata 10. Key sample characteristics are presented in Table 1.

\section{Food items}

Due to the lack of comprehensive dietary surveys and detailed studies on consumption in Lebanon, we resort to a study by Nasreddine, Hwalla, Sibai, Hamzé, and ParentMassin (2006) on the adults' food consumption patterns in Beirut and its suburbs to determine our food basket. This survey-based study, conducted in 2001 on a representative sample of 444 Lebanese adults aged 24 to 54 , collected data on their daily food intakes and majorly consumed food products with the aim of characterizing food consumption patterns in Lebanon. Accordingly, food items which were found to contribute the most to the average daily intakes were selected and the final food basket we adopted consisted of 17 products: bread, rice, fresh cow meat, fresh chicken meat, fresh milk, powdered milk, labneh ${ }^{\mathrm{a}}$ yoghurt, orange, bananas, apples, watermelon, lettuce, tomato, cucumber, potato and white cheese. The selected food basket and its constituents are consistent with the items identified in the FAO balance sheets as major components of food supply in Lebanon for the 2004/2007 period.

Given that the quantities consumed are reported at the household level assigning the same quantities for all members of the same household, we assume that the food is equally distributed within the family and check for outliers in expenditures and quantities consumed before running the model. To facilitate the estimations, the 17 food items were aggregated into 5 categories: (i) bread, (ii) rice, (iii) meats (fresh cow meat \& fresh chicken meat), (iv) dairy products (fresh milk, powdered milk, labneh, yoghurt, white cheese) and (v) fruits and vegetables (orange, banana, apple, watermelon, lettuce, tomato, cucumber, and potato).

Table 1 Sample characteristics

\begin{tabular}{lc}
\hline Variable & Mean \\
\hline Socioeconomic characteristics & \\
Household size & 4.3 \\
Age of head of household & 50.1 \\
Total yearly household expenditure & $\$ 18,702$ \\
Primary education & $35.9 \%$ \\
University education & $6.6 \%$ \\
Geographical distribution (by governorate) & \\
Beirut & $7.9 \%$ \\
Mount Lebanon & $37.0 \%$ \\
Northern Lebanon & $14.7 \%$ \\
Bekaa & $17.6 \%$ \\
Southern Lebanon & $12.6 \%$ \\
Nabatieh & $10.2 \%$ \\
\hline
\end{tabular}




\section{Empirical model}

The empirical analysis proceeds in two stages. In the first stage we estimate food demand elasticities and changes in quantities consumed while in the second stage we convert these quantities into changes in macro/micronutrients and vitamins consumed, in order to evaluate the loss/gain in nutritional terms.

\section{The almost ideal demand system model}

To model households' consumption and expenditure decisions, we use the Almost Ideal Demand System (AIDS) developed by Deaton and Muellbauer (1980) which expresses the shares of household's budget allocated on different food items as a linear function of the logarithm of real total expenditure and relative prices. The AIDS demand equation can be written as follows:

$$
w_{i}=\alpha_{i}+\sum_{j=1}^{N} \gamma_{i j} \ln p_{j}+\beta_{i} \ln (x / P)+u_{i}
$$

where $P$ is a price index defined by:

$$
\ln P=\alpha_{0}+\sum_{k=1}^{N} \alpha_{k} \ln p_{k}+\frac{1}{2} \sum_{j=1}^{N} \sum_{k=1}^{N} \gamma_{k j} \ln p_{k} \ln p_{j}
$$

$w_{i}$ is the budget share allocated to commodity $i ; x$ is the total expenditure; $p$ the relative price of commodity $x ; \alpha, \beta$ and are parameters to be estimated and $u$ an error term.

The theoretical restrictions of demand functions (additivity, homogeneity and symmetry) are imposed by means of restrictions (3), (4) and (5), respectively:

$$
\begin{aligned}
& \sum_{i=1}^{N} \alpha_{i}=1, \sum_{i=1}^{N} \beta_{i}=0, \sum_{i=1}^{N} \gamma_{i j}=0 \\
& \sum_{j=1}^{N} \gamma_{i j}=0 \\
& \gamma_{i j}=\gamma_{j i}
\end{aligned}
$$

Restriction (3) forces budget shares to add up to 1, restriction (4) imposes the condition that a proportionately uniform change in the prices of all commodities does not impact the shares purchased of each of these commodities, and restriction (5) imposes consistency on the choices of consumers.

To control for regional variations, we include a vector of regional dummies $\left(V_{i}\right)$ which take a value of 0 for peripheral areas and 1 for central ones ${ }^{\mathrm{b}}$. Thus, the final regression is:

$$
w_{i}=\alpha_{i}+\sum_{j=1}^{N} \gamma_{i j} \ln p_{j}+\beta_{i} \ln (x / P)+\varnothing V_{i}+u_{i}
$$

The effect of changes in real expenditures on the budget share of food item $i$ is detected by $\beta_{i}$ which takes a negative sign for necessities and a positive sign for luxuries. 
The effect of change in the price of any other food item $j$ is captured by $\gamma_{i j}$. The model proceeds by replacing $\ln P$ by its expression in equation (1) or (6) and estimating the final regression.

\section{Food demand elasticities}

Estimating equation (6) allows the derivation of the Marshallian (uncompensated), Hicksian (compensated) and expenditure elasticities. Since we are more interested in exploring substitution effects rather than income effects; we focus on Hicksian price elasticities.

For a commodity $i$, the Hicksian elasticity $\varepsilon_{i j}$ with respect to commodity $j$ is computed as follows:

$$
\varepsilon_{i j}=\frac{\gamma_{i j}}{w_{i}}+w_{j}-\partial_{i j}
$$

where that $\partial_{i j}$ is the Kronecker delta which is equal to 1 in case of own-price elasticity and 0 for cross-price elasticities. These elasticities are then used to compute the percentage change in quantities consumed of each food category at the new price levels assuming that the elasticity of all items within the same category is constant ${ }^{\mathrm{c}}$.

Thus the percentage change in quantity consumed of any food item $i$ is as a result of price change is computed by:

$$
\% \Delta Q_{i}=\% \Delta p_{i} \times \varepsilon_{i i}+\sum_{j \neq i}^{N-1}\left(\% \Delta p_{j} \times \varepsilon_{i j}\right)
$$

where $\varepsilon_{i i}$ and $\varepsilon_{i j}$ are own- and cross-price elasticities and $\% \Delta p$ the percentage change in price from 2004 to 2008 specified in Table 2 . It follows that the new quantity consumed $Q_{i}^{*}$ will be:

$$
Q_{i}^{*}=\left(1+\% \Delta Q_{i}\right) \times Q_{i}
$$

where $Q_{i}$ is the original quantity consumed ${ }^{\mathrm{d}}$.

\section{Changes in micronutrients and vitamins}

To estimate nutritional changes, eight nutrients were selected: protein, zinc, potassium, vitamin $\mathrm{A}$, vitamin $\mathrm{C}$, calcium, iron and folate. The choice of these macro and micronutrients was based on two main criteria. First, they are recognized for their indispensability for physical and cognitive activity and growth and for maintaining a healthy and well- functioning immune system and metabolic processes (WHO, \& FAO 2006). Second, their average intakes were identified in the available literature on Lebanon as inadequate (El-Hajj Fuleihan et al. 2001; Hwalla et al. 2004; Salamoun et al. 2005; Sibai et al. 2003). Thus, the higher food prices are expected to accentuate these inadequacies.

The second step consisted of converting quantities consumed of food to their nutrient content. For this purpose, we used the software Nutritionist Pro Diet Analysis $(\text { version } 1.2)^{\mathrm{e}}$ to compute the yield $n$ of each nutrient $j$ per gram of each food item $i$. 
Table 2 Consumer prices for food items (LBP/Kg; 1 is approximately LBP1, 500)

\begin{tabular}{lccc}
\hline Food item & Price in $\mathbf{2 0 0 4}$ & Price in 2008 & Change \\
\hline White Arabic bread & 1,000 & 1,339 & $34 \%$ \\
Rice & 3,000 & 4,000 & $33 \%$ \\
Fresh cow meat & 8,710 & 10,168 & $17 \%$ \\
Fresh chicken meat & 3,337 & 4,386 & $31 \%$ \\
Fresh milk & 987 & 972 & $-2 \%$ \\
Powdered milk & 591 & 827 & $40 \%$ \\
Labneh (dried yoghurt) & 3,941 & 5,478 & $39 \%$ \\
Yoghurt & 2,230 & 3,078 & $38 \%$ \\
White cheese & 5,228 & 7,162 & $37 \%$ \\
Orange & 1,367 & 1,685 & $23 \%$ \\
Banana & 1,325 & 1,344 & $1 \%$ \\
Apple & 1,634 & 2,027 & $24 \%$ \\
Watermelon & 824 & 963 & $17 \%$ \\
Lettuce & 802 & 929 & $16 \%$ \\
Tomato & 1,112 & 1,352 & $22 \%$ \\
Cucumber & 1,051 & 1,312 & $25 \%$ \\
Potato & 716 & 1,012 & $41 \%$ \\
\hline
\end{tabular}

Source: Ministry of Agriculture, 2011.

The total amount of nutrient $j$ consumed $\left(T N_{j}\right)$ by the household at the initial food prices of 2004 was then calculated as follows:

$$
T N_{j}=\sum_{i=1}^{N} n_{j i} \times Q_{i}
$$

Similarly, $T N_{j}^{\prime \prime}$ at the 2008 food prices was calculated at:

$$
\begin{aligned}
& T N_{j}^{*}=\sum_{i=1}^{N} n_{j i} \times Q_{i}^{*} \\
& \% \Delta T N_{j}=\frac{T N_{j}^{*}-T N_{j}}{T N_{j}} \times 100
\end{aligned}
$$

The choice of percentage change in nutrient intake as indicator of risk of malnutrition was motivated by the lack of detailed individual-level data required to compute commonly used indicators such as z-scores and adult equivalence ratios. Additionally, we computed the changes in nutrient consumption by governorate to identify the areas which were affected most by the food-price shock and direct our policy recommendations based on these findings.

\section{Results and discussion} AIDS model estimates

The AIDS model estimates are presented in Table 3. The estimated effects of change in real expenditure $\left(\beta_{i}\right)$ in the table are significantly positive for all food categories except bread, which has a significantly negative coefficient, indicating that only bread is consumed by Lebanese households as a necessity. The estimated effect of changes in 
Table 3 AIDS model estimates ${ }^{a}$

\begin{tabular}{|c|c|c|c|c|c|}
\hline & White bread & Rice & Meats & Dairy & Fruits \& veg. \\
\hline \multicolumn{6}{|l|}{ Log price $\left(\gamma_{i j}\right)$} \\
\hline \multirow[t]{2}{*}{ Bread } & $1.76 \mathrm{E}-03$ & $2.72 \mathrm{E}-03$ & $1.05 \mathrm{E}-03$ & $2.52 \mathrm{E}-03$ & $-2.99 \mathrm{E}-03$ \\
\hline & $(0.80)$ & $(2.72)$ & $(1.56)$ & $(9.47)$ & $(-2.51)$ \\
\hline \multirow[t]{2}{*}{ Rice } & $2.72 \mathrm{E}-03$ & $-4.41 E-03$ & $2.21 \mathrm{E}-04$ & $2.21 \mathrm{E}-04$ & $1.25 \mathrm{E}-03$ \\
\hline & $(2.72)$ & $(-4.37)$ & $(0.87)$ & $(2.26)$ & $(2.26)$ \\
\hline \multirow[t]{2}{*}{ Meats } & 1.05E-03 & $2.21 \mathrm{E}-04$ & $-6.15 E-03$ & $3.26 \mathrm{E}-03$ & $1.62 \mathrm{E}-03$ \\
\hline & $(1.56)$ & $(0.87)$ & $(-7.95)$ & $(10.15)$ & $(3.12)$ \\
\hline \multirow[t]{2}{*}{ Dairy } & $2.52 \mathrm{E}-03$ & $2.21 \mathrm{E}-04$ & $3.26 \mathrm{E}-03$ & $-7.24 \mathrm{E}-03$ & $1.24 \mathrm{E}-03$ \\
\hline & $(9.47)$ & $(2.26)$ & $(10.15)$ & $(-24.45)$ & $(5.42)$ \\
\hline \multirow[t]{2}{*}{ Fruits \& Veg. } & $-2.99 \mathrm{E}-03$ & $1.25 \mathrm{E}-03$ & $1.62 \mathrm{E}-03$ & $1.24 \mathrm{E}-03$ & $-1.12 \mathrm{E}-03$ \\
\hline & $(-2.51)$ & $(2.26)$ & (3.12) & $(5.42)$ & $(-0.94)$ \\
\hline \multirow[t]{2}{*}{ Expenditure $\left(\beta_{i}\right)$} & $-2.93 \mathrm{E}-03$ & $8.45 \mathrm{E}-04$ & $5.65 \mathrm{E}-03$ & $2.35 \mathrm{E}-03$ & $2.45 \mathrm{E}-03$ \\
\hline & $(-7.90)$ & $(7.39)$ & (33.9) & (32.64) & $(19.25)$ \\
\hline \multicolumn{6}{|c|}{ Regional dummies } \\
\hline \multirow[t]{2}{*}{ North } & $1.55 \mathrm{E}-02$ & $2.75 \mathrm{E}-03$ & $1.08 \mathrm{E}-02$ & $7.70 \mathrm{E}-03$ & $8.92 \mathrm{E}-03$ \\
\hline & $(22.71)$ & (14.09) & $(9.87)$ & $(11.04)$ & (13.76) \\
\hline \multirow[t]{2}{*}{ Bekaa } & $9.46 \mathrm{E}-03$ & $2.40 \mathrm{E}-04$ & $2.68 \mathrm{E}-03$ & $-1.52 \mathrm{E}-03$ & $4.69 \mathrm{E}-03$ \\
\hline & $(13.4)$ & $(1.18)$ & $(2.37)$ & $(-2.09)$ & $(6.97)$ \\
\hline \multirow[t]{2}{*}{ South } & $1.37 \mathrm{E}-02$ & $2.13 \mathrm{E}-03$ & $1.95 \mathrm{E}-02$ & $2.70 \mathrm{E}-03$ & $7.04 \mathrm{E}-03$ \\
\hline & (19.62) & $(10.55)$ & $(17.3)$ & (3.73) & $(10.5)$ \\
\hline \multirow[t]{2}{*}{ Nabatieh } & $4.81 \mathrm{E}-03$ & $2.67 \mathrm{E}-03$ & $1.22 \mathrm{E}-02$ & $1.71 \mathrm{E}-03$ & $7.40 \mathrm{E}-03$ \\
\hline & $(6.36)$ & $(12.27)$ & $(10.06)$ & $(2.19)$ & $(10.23)$ \\
\hline$R$-squared & 0.12 & 0.07 & 0.07 & 0.09 & 0.05 \\
\hline
\end{tabular}

${ }_{\mathrm{a}}$-values are reported in parentheses; coefficients significant at the 0.05 level are reported in bold.

relative prices $\left(\gamma_{i j}\right)$ varied greatly across food categories. Starting with the bread share equation, the bread price coefficient is positive, yet insignificant. The coefficients of the prices of rice, meats, and dairy products are all positive, and are significant except for meats. Thus, an increase in the relative prices of these products increases the budget share allocated to bread. On the other hand, the price coefficient for fruits and vegetables is significantly negative, which means that an increase in the price of this food category will lower the share of expenditure on bread.

As for the rice share equation, the rice price coefficient is significantly negative, while the price coefficients of bread, meats, dairy products and fruits and vegetables are all significantly positive, and also are significant except for meats. Similarly, in the meats share equation, the meats price coefficient is negatively significant while those for the remaining categories are all positive, though only significantly so for dairy products and fruits and vegetables. For the dairy share equation, the price coefficient for dairy products is significantly negative while those for the remaining categories are all significantly positive. Finally, in the fruits and vegetables share equation, as in the previous non-bread categories, the fruits and vegetables price coefficient is significantly negative and those for the remaining categories significantly positive. Moving to the regional dummies, coefficients are positive for all food categories are positive (except for Bekaa in the dairy products category) and significant (except for Bekaa in the rice category), 
suggesting that households living in peripheral areas generally tend to spend more money on all food categories compared to those living in the central areas. These results are better understood and explained in light of the estimated Hicksian elasticities, as they clarify the relative position of each category compared to the other categories.

\section{Compensated elasticity estimates}

Compensated own and cross-price elasticity estimates are presented in Table 4, and their joint sampling distribution was approximated by means of the delta method ${ }^{\mathrm{f}}$. As expected, the own-price elasticities obtained were all significantly negative and generally high in absolute value for all categories, with the highest for rice and the lowest for bread $^{\text {g }}$. Moreover, the values obtained indicate that the demand for rice is the most highly elastic, followed by meats, dairy products and fruits and vegetables, the latter being only slightly elastic. On the other hand, the demand for bread is slightly inelastic. This result is not surprising given that the government has been forcing a ceiling on the price of bread for years. As for cross- price elasticities, as expected, these are positive and significant for all food category pairings except for bread and fruits and vegetables, where elasticity is negative and significant only at the 10 percent level. This result suggests that in the context of budget reallocation, only those two categories are perceived as complements whereas all other food categories are perceived as substitutes to each others as well as to bread and fruits and vegetables. These elasticities are consistent with the AIDS model estimates.

The percent changes in quantities consumed of each of the 17 food items after the $2004 / 2008$ price changes are calculated and reported in Table 5. According to this table, the quantities consumed of rice, red meat, fresh milk and fruits and vegetables, except cucumber, increased whereas the quantities consumed of bread, chicken meat and all dairy products, except fresh milk, decreased. The two-directional change in consumption signals the potential trade-off or substitution among different food items. In fact, the price of fresh milk decreased by 2 percent which may justify the increase in its consumption. Moreover, it is usually used by Lebanese households, especially in rural areas, to make yoghurt, labneh and white cheese which makes it a good and affordable source and alternative for these products. In terms of meats, the consumption chicken meat is replaced by red meat given that the increase in price of chicken

Table 4 Own and cross-price compensated elasticity estimates ${ }^{a}$

\begin{tabular}{llllll}
\hline & Bread & Rice & Meats & Dairy & Fruits \& veg. \\
\hline Bread & -0.903 & & & & \\
& $(-10.02)$ & & & & \\
Rice & 0.115 & -2.163 & & & \\
& $(2.81)$ & $(-8.11)$ & & & \\
Meats & 0.086 & 0.102 & -1.100 & & \\
& $(3.11)$ & $(1.50)$ & $(-61.16)$ & & \\
Dairy & 0.124 & 0.079 & 0.096 & -1.330 & -1.013 \\
& $(11.36)$ & $(3.05)$ & $(12.92)$ & $(-92.68)$ & $(-23.73)$ \\
Fruits \& Veg. & -0.095 & 0.358 & 0.065 & 0.088 & $(7.93)$ \\
& $(-1.94)$ & $(2.45)$ & $(5.41)$ & & \\
\hline
\end{tabular}

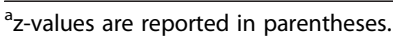


Table 5 Percent changes in consumption of selected food items as a result of the 2008 food-price shock

\begin{tabular}{llll}
\hline Food category & \% change & Food category & \% change \\
\hline Rice & $11.3 \%$ & Orange & $1.8 \%$ \\
White bread & $-19.3 \%$ & Banana & $24.1 \%$ \\
Bovine meat & $13.3 \%$ & Apple & $0.8 \%$ \\
Poultry meat & $-2.1 \%$ & Watermelon & $7.9 \%$ \\
Fresh milk & $58.7 \%$ & Lettuce & $8.9 \%$ \\
Powdered milk & $-26.9 \%$ & Tomato & $2.8 \%$ \\
Labneh & $-25.6 \%$ & Cucumber & $-0.3 \%$ \\
Yoghurt & $-24.3 \%$ & Potato & $-16.5 \%$ \\
Cheese & $-22.9 \%$ & & \\
\hline
\end{tabular}

(31 percent) was much larger than that of red meat (17 percent). The increase in consumption of major fruits and vegetables may be attributed to the smaller increase in their prices compared to the other products in the food basket and to their abundance in the market at low prices.

We have compared some of these changes to the ones derived from the FAO's Food Balance Sheets (FBS) (available from http://faostat.fao.org/site/368/default.aspx) where counterparts in those latter were available. These were bovine meat, poultry meat, apples, bananas, oranges, tomatoes, potatoes and rice. The concordance between the two sources was not close. The signs of the changes in consumption agreed only for half the considered food items, and were of similar magnitude only for two items, namely rice (14.0 percent in FBS vs. 11.3 percent in our study) and bovine meat (12.8 vs. 13.3 percent). For apples and tomatoes, the changes' signs aligned, but the magnitudes were widely different, with the FBS yielding changes that are an order of magnitude larger than our estimates (14.7 vs. 0.8 percent for apples and 30.5 vs. 2.8 percent for tomatoes). For bananas, oranges, potatoes and poultry meat, the FBS yielded changes that were of opposite sign to those we have obtained in our study. Indeed we argue the FBS results as very crude approximations of dietary intake at best, since they represent food availability rather than actual food consumption data (Nasreddine et al. 2006). Hence do not take account of actual wastes and production gluts which are very common in Lebanon. Moreover, our results better reflect price changes and the resulting consumers' adjustments to them. This said, these discrepancies call for caution in the interpretation of our findings.

\section{Nutritional impacts}

Our estimates show that the quantities consumed of the eight selected nutrients (Table 6) decreased in general as a result of the food-price shock and attendant changes in consumption patterns. Nationally, the average decrease in intake varied between a maximum of 16.3 percent for calcium and a minimum of 2.8 percent for vitamin C. In terms of the geographical distribution of these impacts, even though all regions experienced a reduction in nutrient intake, the largest losses for all vitamins and micronutrients except folate occurred in Beirut and Mount Lebanon, while the smallest reductions occurred in the Bekaa. Such results are not surprising given that the Bekaa is the breadbasket of Lebanon and a larger share of families living there practice farming 
Table 6 Percent changes in intakes of selected nutrients as a result of the 2008 food-price shock

\begin{tabular}{llllllll}
\hline Nutrient & Overall & Beirut & Mt. Lebanon & North & Bekaa & South & Nabatieh \\
\hline Protein & $-11.7 \%$ & $-12.5 \%$ & $-13.1 \%$ & $-12.1 \%$ & $-9.4 \%$ & $-11.0 \%$ & $-10.8 \%$ \\
Potassium & $-8.1 \%$ & $-9.6 \%$ & $-9.8 \%$ & $-7.7 \%$ & $-4.4 \%$ & $-7.8 \%$ & $-8.2 \%$ \\
Vitamin A & $-5.8 \%$ & $-10.4 \%$ & $-8.5 \%$ & $-5.2 \%$ & $-1.1 \%$ & $-4.9 \%$ & $-6.3 \%$ \\
Vitamin C & $-2.8 \%$ & $-3.0 \%$ & $-3.2 \%$ & $-3.7 \%$ & $-0.6 \%$ & $-2.9 \%$ & $-4.0 \%$ \\
Calcium & $-16.3 \%$ & $-20.3 \%$ & $-18.7 \%$ & $-14.7 \%$ & $-9.9 \%$ & $-17.2 \%$ & $-16.9 \%$ \\
Iron & $-3.2 \%$ & $-4.5 \%$ & $-4.0 \%$ & $-4.0 \%$ & $-0.5 \%$ & $-2.6 \%$ & $-4.0 \%$ \\
Folate & $-14.5 \%$ & $-13.3 \%$ & $-15.4 \%$ & $-15.0 \%$ & $-13.1 \%$ & $-14.6 \%$ & $-13.7 \%$ \\
Zinc & $-11.3 \%$ & $-11.8 \%$ & $-12.4 \%$ & $-11.5 \%$ & $-9.2 \%$ & $-10.8 \%$ & $-10.9 \%$ \\
\hline
\end{tabular}

and agriculture-related activities. This is particularly important because in times of food crisis, a farmer may have the option of saving part of his output, if not all of it, for personal consumption whereas urban families, especially poor ones, may not have such an option.

Due to the absence of official data on nutrient consumption, we resort to the existing literature on nutrient consumption and deficiencies in Lebanon to interpret the significance of our results. In terms of vitamins, the reduced intake of vitamin A, found usually in milk, potatoes, green leafy vegetables, carrots, oranges and fish, may be attributed to a large extent to the drop in the consumptions of potatoes and powdered milk (Table 5), adding insult to the injury of low fish consumption in the country (Nasreddine et al. 2006). Indeed data from the "Nutrition and Non-Communicable Disease Risk Factor Survey" on vitamin A intakes in Lebanon indicate that around 40 percent of children aged five to ten and 63 percent of adolescents are already consuming less than two thirds of the recommended daily intake (N. Hwalla, unpublished data, 2009). Therefore, this extra reduction in vitamin A intake is problematic under the prevailing consumption patterns and may have serious implications on the nutritional status of children and adolescents, given its vital role in the normal growth and repair of all body tissues as well as the sound functioning of the visual and immune systems (Kennedy, Nantel, \& Shetty 2003).

As for vitamin C, Nasreddine et al. (2006) found that the consumption of fruits and vegetables, its major source, is slightly below the recommended intake. Nevertheless, our estimated intake reduction is not expected to have serious implications given the abundance of a wide variety of fruits and vegetables in the local market at relatively low prices. Finally, the substantial reduction in folate intake may well increase the risk of anemia, neurological problems and fetal defects, especially given the already low intake of this vitamin among the Lebanese population ( $\mathrm{Al}$ Khatib et al. 2006; N. Hwalla, unpublished data, 2009). Such low intakes of folate among Lebanese households may be the consequence of high intakes of refined cereals which are generally poor in folate and a low intake of leafy greens, legumes and fruits which constitute a rich source of this nutrient.

In terms of micronutrients, the substantial reduction of calcium intake exacerbates an already alarming situation. A study by El-Hajj Fuleihan et al. (2001) on the calcium intakes among Lebanese schoolchildren indicates that the average intakes of calcium fall below the recommended daily intake by 45 percent. At the adults' level, a nationally 
representative dietary survey found that around 66 percent of Lebanese adults consume on average 37 percent less than the daily-recommended intake (N. Hwalla, unpublished data, 2009). The low intakes of calcium can be the consequence of low consumption of dairy products and milk. Note that calcium deficiencies can cause rickets at early childhood, and osteoporosis and hypertension at later ages. As for potassium, the overall reduction in intake takes place against a backdrop of children and adolescents meeting less than half the recommended dietary intake (N. Hwalla, unpublished data, 2009). This low consumption may not be highly problematic in itself; however when coupled with the increasing consumption of sodium, recorded in the same survey, it may increase the risk of hypertension and cardiovascular diseases. Similarly to calcium, the reduction in potassium consumed was higher in Beirut and Mount Lebanon than other areas, especially Bekaa.

In terms of iron intake, the image does not differ much from that of calcium and potassium, where reduction in intake, and hence increase risks of anemia, takes place against a background of widespread deficiency among children (N. Hwalla, unpublished data, 1998) and adults (Al Khatib et al. 2006; Hwalla et al. 2004). In terms of zinc intake, the average reduction in intake is substantial. Zinc intake in Lebanon is already low for all age categories (FAO 2007), be they children, adolescents (N. Hwalla, unpublished data, 2009) or adults (Obeid et al. 2008). Therefore this additional reduction in zinc intake will surely contribute to zinc-deficiency related risks such as growth retardation, mental disturbances, dermatitis and higher risks of infection.

At the macronutrient level, the consumption of proteins decreased, on average, by around 12 percent, and was highest in Mount Lebanon and Beirut and lowest in Bekaa. While bovine meat and fresh milk consumptions have increased, the consumption of other protein-rich food items has decreased (poultry meat, powdered milk, labneh, yoghurt and cheese) such that the net protein intake decreased as well. Data indicate that the mean intake of protein falls within the acceptable ranges for both children and adults. Therefore, this reduction may not be problematic, yet it still requires attention with the reduction in the consumption of poultry and dairy products (Table 5) and the low consumption of fish highlighted in Nasreddine et al. (2006).

\section{Conclusion}

In this study, we analyze the nutritional implications of the 2004/2008 food crisis focusing on nutrients' consumption as a key indicator of the risk of malnutrition and using data drawn from the 2004 National Survey of Household Living Conditions in Lebanon. The analysis is based on an almost ideal demand system (AIDS) model of expenditure shares for various aggregated food categories. From this model, compensated price elasticities are derived and used in the estimation of percentage changes in macro and micronutrients and vitamins intakes. According to our estimates, food price increases significantly lowered Lebanese households' consumption of macro/micronutrient and vitamins. Even though this reduction in nutrient intakes is experienced in the all the six Lebanese governorates, it varies significantly across them. The greatest reductions occur in Beirut and Mount-Lebanon and the lowest in Bekaa, suggesting that urban families may be at greater risk than rural families. Linking these results to the existing studies of the Lebanese nutritional status and dietary habits, the losses in intakes of zinc, calcium, folate and iron are found to be most significant and problematic 
particularly because the Lebanese population already has been suffering from highly deficient intakes of these micronutrients.

This analysis of the nutritional repercussions of the food-price shock unveils the pressing need for public interventions to fight and prevent nutrients' deficiencies in specific and improve the command of consumers and the economy in general over food. Proposing concrete policy proposals to mitigate the nutritional effects of the food-price shock is not the primary focus of this paper. Yet it appears that the further aggravation of micronutrients' deficiencies could be alleviated by means of fortification. This technique uses widely accessible and consumed foods as conduit for the delivery of one or more micronutrients (Kennedy et al. 2003), and is mainly used for mild deficiencies or for prevention. Based on the model findings, such a measure could include folate, iron and calcium which can be added to milk and dairy products as well as juices. Fortification can be applied as an independent policy or incorporated into other policies such as school feeding programs. Moreover, such a policy could be accompanied by a marketing and distribution strategy to encourage the purchasing of fortified food items and ensure their availability in all regions.

This said, it has been brought to our attention by an anonymous reviewer that the further estimation of nutrient elasticities (Ecker \& Qaim 2011; Pitt 1983; Sahn 1988) would help improve the discussion of our findings and policy implications. This is a legitimate point, as nutrient elasticities would facilitate the simulation of the nutritional impacts of various income and price related policies. This is work that we intend to pursue elsewhere in the near future. Herein, this concern is mitigated by the fact that our primary focus is the estimation of the effects on households' nutrition of a single economic conjuncture, namely the 2008 food-price shock, rather than perform policy simulations. Therefore, rather than derive nutrient elasticities as building blocks for the forecasting of various policies' nutritional impacts, we directly evaluated those latter by means of the changes in nutrients' intake resulting from the discrete shock in food prices.

Despite the robustness of our estimates, their interpretation requires caution. First, it is essential to keep in mind that these results don't represent the exact changes in households nutrients consumption that resulted from the prices variations but rather draw a general pattern of these changes and an indication of their signs and magnitudes. In fact, they may be conservative estimates of the actual changes. Second, the assumption of constant elasticity for items within the same category may be too restrictive. Third, the absence of detailed figures on food expenditures and quantities consumed at the individual level in the survey may hide interesting and important aspects of malnutrition in the country. The fourth and most important limitation was the absence of official data on the anthropometric conditions and nutrient intakes at both the pediatric and adult level and the lack of national nutritional and food safety guidelines to assess the significance of the reductions in nutrient intake in the Lebanese context. Thus, the significance of some nutrient intake reductions may lack some precision due to the absence of clear benchmarks to compare the estimated results with.

\section{Endnotes}

${ }^{a}$ Labneh: dried yogurt.

${ }^{b}$ Peripheral areas are the Bekaa, Nabatieh, North and South Lebanon governorates, which are significantly less urbanized than the capital Beirut and the densely populated 
Mount-Lebanon in which are located the capital's suburbs and satellite towns. This division was intended to explore the effects of rural-urban disparities on the consumption of foods and nutrients.

${ }^{c}$ The original estimation was attempted with the disaggregated food items and hence different elasticities within categories. However, the resulting large number of constraints that had to be imposed was such that a model could not be identified.

${ }^{\mathrm{d}}$ An anonymous reviewer has expressed concern over the use of elasticity estimates based on 2004 data to predict changes in the consumption of various food items after the 2008 price-shock. S/he argues that the assumption that elasticities will have constant values over those years is unrealistic. We think this concern is legitimate. Unfortunately, the 2004/2005 multi-purpose household survey is the most recent nationally representative household budget and expenditure survey undertaken in the country. More recent national surveys did not include expenditure modules, focusing only on socio-economic characteristics. As for elasticity estimates, while it is true that their values might change over time, it is plausible to assume that this change would not be substantial over a short period of four years, as underlying demand behavior would need time to adjust to various shocks and changes in the economy.

${ }^{\mathrm{e}}$ The Nutritionist Pro Diet Analysis software provides complete nutrient analysis of diets, customized recipes and menus as well as dietary recalls/records with an up-todate food and nutrient database. Further details about this software can be found on its web page, http://www.nutritionistpro.com.

${ }^{\mathrm{f}}$ The Delta method is commonly used to test hypotheses about non-linear combinations of parameter estimates, such as the elasticities at hand, for which moments of the sampling distribution cannot be analytically derived. In such cases, the Delta method approximates the requisite standard errors, $z$-values and p-values by means of firstorder Taylor series approximations.

${ }^{\mathrm{g}}$ The significance of elasticity estimates depends not only on the significance of the $\log$-price parameters $(\gamma)$, but also on the expenditure parameters $(\beta)$, which are very highly significant for all food categories. It is therefore no surprise that certain food categories of combinations of food categories have significant own- and cross-price elasticities, respectively, when their corresponding log-price parameters are insignificant.

Competing interests

The authors declare that they have no competing interests.

Acknowledgments

None.

Author details

${ }^{1}$ Department of Agricultural Sciences, Faculty of Agricultural and Food Sciences, American University of Beirut, P.O. Box 11-0236 Riad el Solh, Beirut 1107-2020, Lebanon. ${ }^{2}$ Department of Nutrition and Food Sciences, Faculty of Agricultural and Food Sciences, American University of Beirut, P.O. Box 11-0236 Riad el Solh, Beirut 1107-2020, Lebanon.

Received: 18 September 2013 Accepted: 8 January 2014

Published online: 24 April 2014

References

Al Khatib L, Obeid O, Sibai AM, Batal M, Adra N, Hwalla N (2006) Folate deficiency is associated with nutritional anaemia in Lebanese women of childbearing age. Public Health Nutrition 9(7):921-927, doi: 10.1017/PHN2005921

Behrman JR (1993) The economic rationale for investing in nutrition in developing countries. World Dev 21(11):1749-1771. doi:10.1016/0305-750 x (93)90081-J

Bowman SA (2006) A comparison of the socioeconomic characteristics, dietary practices, and health status of women food shoppers with different food price attitudes. Nutr Res 26(7):318-324. doi:10.1016/j.nutres.2006.06.012 
Central Administration of Statistics (2005). Household Expenditure. [Online database]. Available from http:/www.cas. gov.lb/index.php/en/demographic-and-social-en/householdexpenditure-en

Cole MA, Neumayer E (2006) The impact of poor health on total factor productivity. J Dev Stud 42(6):918-938. doi:10.1080/002203806007746881

Deaton A, Muellbauer J (1980) An almost ideal demand system. [Article]. Am Econ Rev 70(3):312-326

Ecker O, Qaim M (2011) Analyzing nutritional impacts of policies: an empirical study for Malawi. World Dev 39(3):412-428. do:10.1016/j.worlddev.2010.08.002

El-Hajj Fuleihan G, Nabulsi M, Choucair M, Salamoun M, Hajj Shahine C, Kizirian A, Tannous R (2001) Hypovitaminosis D in healthy schoolchildren. Pediatrics 107(4):e53

FAO (2007) Nutrition country profile - Lebanon. Nutrition and Consumer Protection Division, Food and Agriculture Organization. Retrieved from ftp://ftp.fao.org/ag/agn/nutrition/ncp/lbn.pdf

FAO (2010) Country Profile: Food Security Indicators - Lebanon. Retrieved from http://www.fao.org/fileadmin/ templates/ess/documents/food_security_statistics/country_profiles/eng/Lebanon_E.pdf

FAO (2013) FAO Food Price Index. [Data file]. Retrieved fom http://www.fao.org/fileadmin/templates/worldfood/ Reports_and_docs/Food_price_indices_data.xls

Hwalla N, Adra N, Jackson RT (2004) Iron deficiency is an important contributor to anemia among reproductive age women in Lebanon. Ecol Food Nutr 43(1-2):77-92. doi:10.1080/03670240490274101

Ivanic M, Martin W (2008) Implications of higher global food prices for poverty in low-income countries. Agric Econ 39(1):405-416. doi:10.1111/j.1574-0862.2008.00347.x

Jensen RT, Miller NH (2008) The impact of food price increases on caloric intake in China. Agric Econ 39(1):465-476. doi:10.1111/j.1574-0862.2008.00352.x

Kennedy G, Nantel G, Shetty P (2003) The scourge of "hidden hunger": Global dimensions of micronutrient deficiencies. Food Nutrition and Agriculture 32:8-16

MoSA, UNDP, \& CAS (2006) Living Conditions of Households. The National Survey of Households Living Conditions 2004. Ministry of Social Affairs, United Nations Development Programme and Central Amdinistration of Statistics, Beirut, Lebanon, Retrieved from http:/www.cas.gov.lb/images/PDFs/Living\%20conditions\%20survey\%202004.zip

Nasreddine L, Hwalla N, Sibai A, Hamzé M, Parent-Massin D (2006) Food consumption patterns in an adult urban population in Beirut, Lebanon. Public Health Nutr 9(2):194-203

Nasreddine L, Naja F, Chamieh MC, Adra N, Sibai AM, Hwalla N (2012) Trends in overweight and obesity in Lebanon: evidence from two national cross-sectional surveys (1997 and 2009). BMC public health 12:798

Obeid O, Elfakhani M, Hlais S, Iskandar M, Batal M, Mouneimne Y, Adra N, Hwalla N (2008) Plasma copper, zinc, and selenium levels and correlates with metabolic syndrome components of lebanese adults. Biol Trace Elem Res 123 (1-3):58-65. doi:10.1007/s12011-008-8112-0

Pitt MM (1983) Food preferences and nutrition in rural Bangladesh. Review of Economics and Statistics 65(1):105-114

Sahn DE (1988) The effect of price and income changes on food-energy intake in Sri Lanka. Econ Dev Cult Chang 36(2):315-340

Salamoun MM, Kizirian AS, Tannous RI, Nabulsi MM, Choucair MK, Deeb ME, El-Hajj Fuleihan GA (2005) Low calcium and vitamin D intake in healthy children and adolescents and their correlates. Eur J Clin Nutr 59(2):177-184. doi:10.1038/sj.ejen.1602056

Sibai AM, Zard C, Adra N, Baydoun M, Hwalla N (2003) Variations in nutritional status of elderly men and women according to place of residence. Gerontology 49(4):215-224

UNDP (2013) The Millennium Development Goals in Lebanon. [Web page] Retrieved April 14, 2013, from http://www. undp.org.lb/WhatWeDo/MDGs.cfm

WHO, \& FAO (2006) Guidelines on food fortification with micronutrients. World Health Organization and Food and Agriculture Organization of the United Nations. Retrieved from http://www.unscn.org/layout/modules/resources/ files/fortification_eng.pdf

World Bank (2013) Food imports (\% of merchandise imports). Retrieved from http://data.worldbank.org/indicator/TM. VAL.FOOD.ZS.UN

World Bank (2014) World Development Indicators (WDI). Retrieved from http://data.worldbank.org/indicator

doi:10.1186/s40100-014-0003-4

Cite this article as: Zaki et al.: The impact of food price increases on nutrient intake in Lebanon. Agricultural and

Food Economics 2014 2:3.

\section{Submit your manuscript to a SpringerOpen ${ }^{\circ}$ journal and benefit from:}

- Convenient online submission

- Rigorous peer review

- Immediate publication on acceptance

- Open access: articles freely available online

- High visibility within the field

- Retaining the copyright to your article

Submit your next manuscript at $\boldsymbol{~ s p r i n g e r o p e n . c o m ~}$ 